Article

\title{
Activism, Advertising, and Far-Right Media: The Case of Sleeping Giants
}

\author{
Joshua A. Braun ${ }^{1, *}$, John D. Coakley ${ }^{1}$ and Emily West ${ }^{2}$ \\ ${ }^{1}$ Journalism Department, University of Massachusetts Amherst, Amherst, MA 01003, USA; \\ E-Mails: jabraun@journ.umass.edu (J.A.B.), johndcoakley@gmail.com (J.D.C.) \\ ${ }^{2}$ Communication Department, University of Massachusetts Amherst, Amherst, MA 01003, USA; \\ E-Mail: ewest@comm.umass.edu \\ * Corresponding author
}

Submitted: 18 June 2019 | Accepted: 10 October 2019 | Published: 17 December 2019

\begin{abstract}
This study examines the international activist movement known as Sleeping Giants, a social-media "campaign to make bigotry and sexism less profitable" (Sleeping Giants, n.d.). The campaign originated in the US with an anonymous Twitter account that enlisted followers in encouraging brands to pull their online advertising from Breitbart News. The campaign achieved dramatic success and rapidly spread to regions outside the US, with other anonymously run and loosely allied chapters emerging in 15 different nations (as well as a regional chapter for the EU). Many of these were initially created to take on Breitbart advertisers in their home countries, but in a number of cases they subsequently turned their attention to disrupting financial support for other far-right news media in-or impacting-their home countries. Based on interviews with leaders of eight Sleeping Giants chapters, as well as the related UK-based Stop Funding Hate campaign, this study examines the Sleeping Giants campaign with respect to its continuity with media activism of previous eras, while also seeking to understand its potential as one of the first high-profile activist campaigns to grapple with the impacts of programmatic advertising on the news ecosystem. In particular, we consider how the campaign's interventions speak to the larger debate around the normative relationship between advertising and the performance of the news ecosystem.
\end{abstract}

\section{Keywords}

activism; corporate social responsibility; hate speech; hyper-partisan news; online activism; online advertising; programmatic advertising; Sleeping Giants

\section{Issue}

This article is part of the issue "Peripheral Actors in Journalism: Agents of Change in Journalism Culture and Practice" edited by Avery E. Holton (University of Utah, USA), Valerie Belair-Gagnon (University of Minnesota-Twin Cities, USA), and Oscar Westlund (Oslo Metropolitan University, Norway / Volda University College, Norway / University of Gothenburg, Sweden).

(C) 2019 by the authors; licensee Cogitatio (Lisbon, Portugal). This article is licensed under a Creative Commons Attribution 4.0 International License (CC BY).

\section{Introduction}

Amid the economic collapse of many ad-driven news publications in the US and elsewhere, a conversation has emerged among media critics and journalism scholars about the future, or lack thereof, of ad-supported journalism. Positions within this dialogue are nuanced and it is thus more accurate to speak of a spectrum of viewpoints than sides in a debate. On one end are scholars like Habermas (2007), Pickard (2014), or McChesney and Nichols (2010), who argue the economic crisis in ad- supported journalism presents an opportunity to finally divorce journalism from the pressures of the market by introducing public funding mechanisms. They draw on the work of Baker (2001) and others, delineating various ways in which reliance on advertising distorts the public mission of journalism. At least some of these scholars see efforts to restore advertising subsidies to news as fundamentally misguided, akin to begging back into a bad relationship.

On the other end of the aforementioned spectrum, scholars like Couldry and Turow (2014) and academic 
researchers affiliated with the Global Disinformation Index (Melford \& Fagan, 2019)-while not averse to the notion of publicly funded journalism-are more focused on the recent impact of behaviorally targeted advertising on news organizations and their output. They frame many of the harms to which digital advertising has contributed-the revenue crisis at news organizations, the rise of click-driven editorial strategies, new opportunities for ad fraud, and heightened monetary incentives for the spread of disinformation and hate speech-as potentially addressable by reforms that would limit fraud, abuse, and marketing surveillance while returning greater advertising subsidies to professional news organizations.

In other words, this spectrum of opinion ranges from revolution to reform - from those who would like to dismantle news organizations' relationship with advertising to those who see the relationship as reparable. As we discuss in this article, this difference in opinion also turns up in significant ways across activist campaigns targeting the advertising industry.

Sleeping Giants is a novel activist campaign aimed at digital advertising that serves as an important provocation, both in the world of media activism and in the academic policy debates surrounding the appropriate relationship between journalism and advertising in the 21st century. Based on interviews with the activists themselves, this study examines Sleeping Giants with respect to its continuity with media activism of previous eras, while also seeking to understand its potential as one of the first high-profile activist campaigns to grapple with the recent impacts of programmatic advertising on the news ecosystem.

The Sleeping Giants campaign centers around two intertwined issues: 1 ) The rapid rise in popularity of right- wing "hyper-partisan news" sites, best exemplified by the ascendance of Breitbart News over the course of the 2016 US presidential election; and 2) the opportunities and threats created within the news ecosystem by contemporary programmatic advertising. To set the stage, we introduce both here.

\subsection{Right-Wing Hyper-Partisan News}

A well-known study conducted by Faris et al. (2017) confirmed what many media watchers had already suspected-namely that Breitbart News, famously described by its erstwhile executive chairman Steve Bannon as a home for the "alt-right," had dominated the information diet of conservative social media users in the US during the 2016 presidential election. Throughout this time, the site played a substantial role in driving the agenda of partisan conservative outlets across the web, ranging from relatively popular publications to sites at the fringes, the latter of which at times drew on Breitbart's more conspiratorial framings of the news to spin up outright hoaxes. Not only had Breitbart and its ilk come to dominate conservative media, they also played an agenda-setting role, drawing mainstream news outlets into covering their favored topics, if only to contest the original, misleading coverage, or the conspiracy theories that evolved from it (Phillips, 2018).

While Breitbart stories have often been flagged as selective and misleading in their interpretation of current events, perhaps of greatest concern to critics is that the site's coverage often toes or crosses the line into hate speech, pushing frames and inflammatory headlines that single out women, migrants, and ethnic minorities in troubling ways (see Figure 1). Outside the US, other farright partisan sites like Boulevard Voltaire (BV; France)

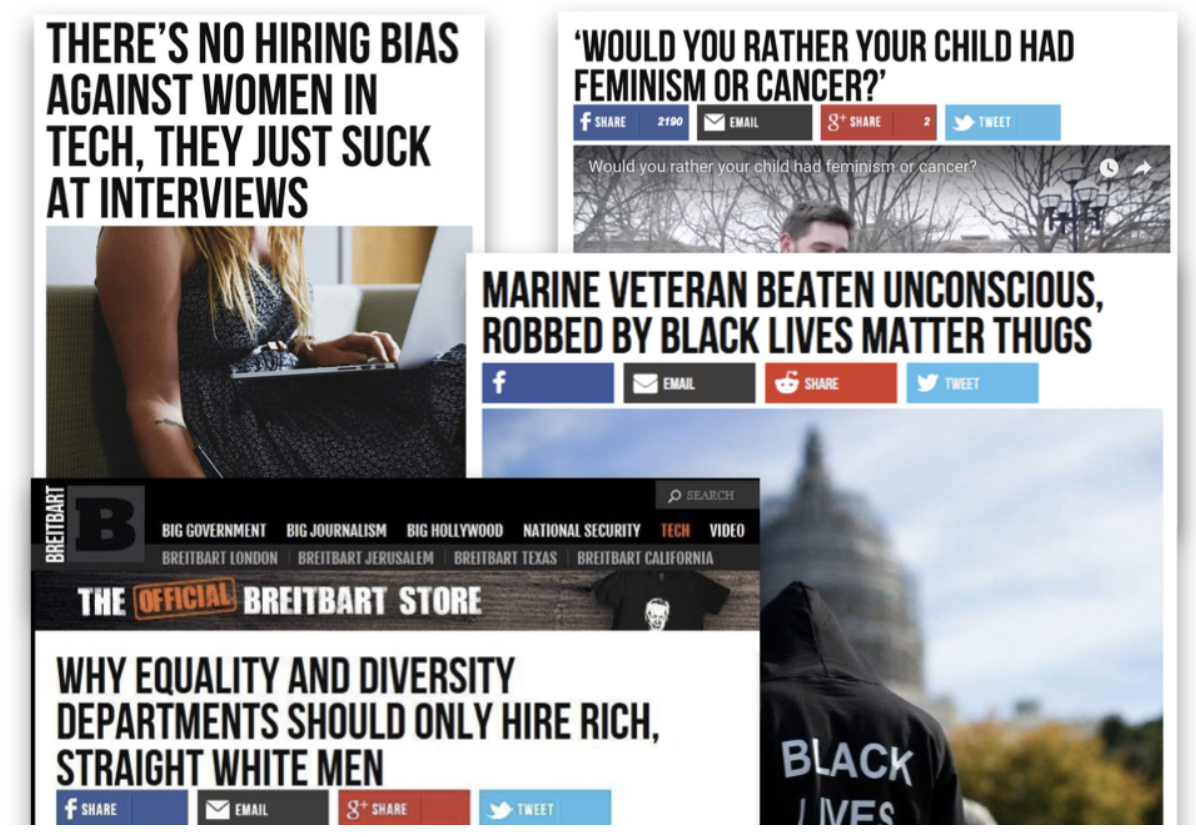

Figure 1. Examples of inflammatory Breitbart News headlines. 
and Nyheter Idag (Sweden) create similarly problematic content, at times apparently influenced by material from Breitbart itself. A common feature among these sites is that they are monetized, in whole or in part, through programmatic advertising.

\subsection{Programmatic Advertising}

Much of the online advertising ecosystem has come to be dominated by programmatic advertising. While programmatic advertising can take a number of forms, most commonly it consists of an online auction that occurs each time a web page is loaded, in which a publisher puts up ad space for sale along with details on the user about to view it. Advertisers bid on the attention of the user based on their perceived desirability as a customer. Intermediaries known as ad-tech firms handle the details of each transaction. These intermediaries are numerous (though they are often owned by the same tech giants) and it is not uncommon for a single transaction to involve four or more ad-tech companies. The resulting complexity of each transaction, combined with the fact that programmatic advertising tends to focus advertisers' attention on reaching desirable users at the expense of editorial context, has meant that until recently advertisers were often unaware of where on the web their ads were appearing (Braun \& Eklund, 2019; McStay, 2017; Melford \& Fagan, 2019; Turow, 2011). This opacity in the supply chain has been readily exploited by proprietors of clickbait sites who spin up viral content featuring miracle diets, strange cosmetic trends, and hoax news articles solely for the purpose of generating a profit from programmatic ads (Bell \& Owen, 2017; Braun \& Eklund, 2019; Fenton \& Freedman, 2017; Melford \& Fagan, 2019; Wu, 2016).

While much of this content would not have garnered advertiser support in the era when brands still relied on editorial context as a proxy for desirable audiences, Malthouse, Maslowska, and Franks (2018, p. 32) note that programmatic advertising has succeeded in separating "the value of the content product from the audience product." When brands can track desirable users across the web, they not only have less incentive now than they once did to think about editorial context, they may see a benefit in reaching those users in the cheapest possible spaces - spaces that tend not to belong to reputable publishers, but to clickbait artists.

This is the economic logic that incentivized the creation of many profit-driven "fake news" sites during the 2016 election and it simultaneously worked to the benefit of hyper-partisan sites like Breitbart News, since they drew traffic with inflammatory headlines that might otherwise have been unpalatable to advertisers. Scholars who study these issues in the advertising ecosystem have not been sanguine about the prospect of self-reform within the ad-tech industry. Braun and Eklund (2019) outlined a variety of ways in which the complexity of the ad-tech ecosystem incentivized firms to act outside the public interest while avoiding responsibility for poor outcomes. Other researchers have similarly argued that some combination of outside forces-political activism, possibly followed by government regulation-are likely to be necessary precursors for reform (e.g., Couldry \& Turow, 2014; Pickard, 2014).

It was significant, then, when the public controversies surrounding "fake news" and sites like Breitbart News in the wake of the 2016 US presidential election arguably created a new concern for editorial context on the part of advertisers. Braun and Eklund (2019) quote ad-tech executive Charlie Tillinghast on this point:

As long as [brands] were reaching the person they wanted, then they were less concerned about the context [in which their ad appeared]. But now they're being accused of essentially funding fake news or...hate speech or conspiracies...by virtue of the fact that their ad is running on that site. That's different. (p. 16)

This moment of tension and vulnerability created an opening for creative activism, which was seized most successfully by Sleeping Giants.

\section{Methods}

Couldry and Turow (2014) and Pickard (2014) have each argued that activism in the digital advertising space is simultaneously essential to reforms in the public interest and significantly complicated by the fact that some of the issues involved are intricate and therefore potentially difficult to mobilize around. Given the notion that activism around programmatic advertising is necessarily complex and therefore challenging, the rapid spread of Sleeping Giants' tactics, which diffused and were adapted across national contexts in the span of a few months, suggests an important intervention in this space. We wanted to investigate the accessibility of the model in its original formation, as well as how it traveled so readily. Here we narrate a significant and recent chapter in media activism across national borders. While not a full crosscomparative analysis of the factors that shaped spin-off campaigns in different national contexts, we look forward to analyzing international differences more fully in future work.

We conducted qualitative semi-structured interviews with the anonymous activists behind as many of the Sleeping Giants chapters as we were able to reach. We began by direct-messaging the original US chapter via one of its social media accounts and obtaining an interview. The interviewee then passed along our call for participation to the other Sleeping Giants chapters. Those interested in participating in the study reached out to us, in some cases referring us to additional chapters. After the culmination of this snowball sample, we reached out directly to the remaining chapters whose direct messages were open on social media. Toward the end of the study we also re-contacted those chapters we had spoken to 
previously whose accounts were still active to conduct follow-up interviews regarding their activities since we first spoke.

We interviewed activists behind eight (out of a total of sixteen) Sleeping Giants chapters, including the US, France, Sweden, Switzerland, Germany, Australia, Netherlands, and the EU. We conducted follow-up interviews with the American and French chapters. At the suggestion of several participants, we also interviewed Richard Wilson, the co-founder of the UK-based activist campaign, Stop Funding Hate, which is similar to Sleeping Giants in a number of respects and has interacted substantively with various Sleeping Giants chapters in ways participants viewed as being integral to their efforts. Interviews averaged 65 minutes in length and were conducted by phone or voice chat, though one interviewee elected to participate by email and two by direct message over social media. In all, 7.6 hours of interview audio were recorded. While our sample coverage was quite good-the interviews represented participation from $50 \%$ of the Sleeping Giants chapters-we took advantage of the fact that our data were of a size that could be reviewed iteratively. The authors listened to, read transcripts of, and made detailed notes on all of the collected interviews. We regularly compared and talked through the notes we had made on the interview data to identify and interrogate emergent themes. Consistent with a "grounded theory" approach (see Glaser \& Strauss, 1967), each interview was ultimately coded according to the themes that emerged from this process.

With the exception of Stop Funding Hate co-founder Richard Wilson, who was a public figure at the time of our interview, and Sleeping Giants US founder Matt Rivitzwhose identity was revealed by the Daily Caller and subsequently published in the national press between our initial and follow-up interviews-all of the activists we spoke with operated anonymously. Though we were able to establish through existing contacts and secure communications that the people with whom we spoke were the real activists behind the Sleeping Giants chapters they claimed to represent, we do not know their real names. Out of respect for their privacy we will use genderneutral pronouns below to represent their quotes.

\section{How Sleeping Giants Works}

Sleeping Giants' central tactic is to invite users to take screenshots of brands' ads appearing on Breitbart News or other target sites, and then to post them to Twitter in a tweet that tags both the brand's Twitter account and the Sleeping Giants account. Often the screenshot will be accompanied by images of inflammatory headlines the target site has posted in the past, to convey a sense of why the placement could be problematic for the advertiser's image. The Sleeping Giants account will often, but not always, retweet the user's callout for the sake of amplification. They will also keep track ofand retweet-the brand's response to the user. In cases where the brand responds by agreeing to remove its ads from Breitbart, Sleeping Giants will add the brand to the public list of advertisers-currently over 4,200that have agreed to block Breitbart from their ad buys. Chapters in different countries maintain analogous lists for their regional targets. The campaign's Twitter account keeps a link to the relevant list, along with simple instructions for users and advertisers, in a pinned tweet, always visible at the top of their profile page (see Figure 2). The US and many other Sleeping Giants chapters also run similar campaigns on Facebook, though in interviews they uniformly said that-for their purposes-they consider Facebook a secondary channel, maintained for reaching users and brands without a Twitter presence.

Pinned Tweet
Sleeping Giants
@slpng_giants
THE SG UPDATED CONFIRMED LIST: bit.ly/2gcSNvW
THE SG FAQ: bit.ly/2hgC9wv
REMOVE ADS YOURSELF: bit.ly/2hzUZin
INQUIRIES: sleepinggiantsinquiries@gmail.com
DEATH THREATS:
sleepinggiantsdeaththreats@gmail.com
HI QUALITY SG MERCH:
sIpnggiants.store
HOW TO BE A GIANT:
1. GO to Breitbart and take a screenshot
of an ad next to some of their content.
2. TWEET the screenshot to the
company with a polite, non-offensive
note to notify them of the placement
3. TAG @s!png_giants so we can keep
track of the progress.
6:42 PM - Feb 21, 2019 - Twitter for iphone

Figure 2. Pinned tweet on the Sleeping Giants US Twitter account, including simple instructions for users.

Sleeping Giants has achieved dramatic success, by some estimates cutting the number of advertisers on Breitbart by $90 \%$ in its first two months of operation (Bhattarai, 2017), though the activists dispute this figure. In addition to the pull-out of advertisers called out by the campaign, one source we spoke with explained they'd heard privately from ad agency executives who saw the impact of Sleeping Giants and more quietly redirected clients' ad buys. The campaign recently won a Webby Award for "Public Service and Activism" and since its inception its model of activism has spread across the globe.

A key to the group's success seems to be the way in which it simplifies involvement by users, both by allowing them to leverage the familiar tools of social media and by breaking potential contributions down into an uncomplicated set of tasks. This lowering of barriers and 
granularity of tasks is in line with successful tactics from past online activist campaigns, such as the circulation by Anonymous of simple instructions and easy-to-use software that allowed ordinary people to participate in distributed denial-of-service actions (Beyer, 2014; Sauter, 2014). It includes features of what scholars like Bruns (2008) argue is uniquely effective about contemporary forms of peer production and is an essential element of what Bennett and Segerberg (2012) have dubbed "connective action" on the part of digitally-enabled social movements.

At the same time, the Sleeping Giants campaign calls to mind far more traditional activist techniques, such as the advertiser boycott.

\subsection{The Treachery of Boycotts}

While Sleeping Giants insists in its public-facing FAQs and other documents that it is not a boycott, it looks an awful lot like one. User replies to callout tweets on the Sleeping Giants Twitter account are replete with threats by users to stop purchasing the brands in question. In thinking through how Sleeping Giants fits into the larger picture of media reform, it is worth puzzling out the similarities and differences between its activities and traditional advertiser boycotts.

During the heyday of network television, Fahey (1991) observed that in many cases consumer boycotts targeting the advertisers on objectionable programming did little to actually harm sales revenues on the part of the affected brands. Rather, the threat of proposed or actual boycotts was primarily reputational. Friedman's (1999) taxonomy of consumer boycotts also underscores this point, drawing a distinction between "marketplaceoriented" and "media-oriented" boycotts. Though the two overlap, they differ in their primary objectives-the former seeks to change companies' behavior by denting sales revenues, while the latter is mostly about the threat of reputational damage to brands.

Many advertiser boycotts, in other words, are primarily undertaken by activists not to impact sales, but to create a news hook that may-if the company does not respond in the desired manner-generate negative coverage and bad publicity that damages public perception of a brand. Thus, while media activism targeting advertisers is sometimes conceptualized as a boycott, it may be more accurate to characterize it as a form of "flak," which Herman and Chomsky (2008) defined as disciplining the media through complaint, or essentially, in the sphere of public relations.

Advertising is conventionally understood to be focused on selling products, but a compelling goal of all advertising (and sometimes the primary goal) is to promote brand awareness, relevance, and positive affect. Therefore, a campaign that puts a brand in a negative light or changes the conversation or meaning of that brand is a significant threat, even if it isn't immediately associated with a decline in sales via an effective boycott.
While scholars have typically associated flak with right-wing activists, who in the 1980s and 1990s became well-known for protesting content on the basis usually of its depictions of sex and sexuality (McAllister, 1996; Rentschler, 2003), it has become a more widely-used tool across the political spectrum. It's also become easier to accomplish outside the structure of a pre-existing organization given the affordances of social media. While flak works especially well if you're well-funded, with lobbyists, lawyers, and connections to journalists, it can also be a tool for less-resourced organizations like Sleeping Giants. When Sleeping Giants wants to critique or praise a brand, it can reach hundreds of thousands of users directly-and even generate news coverage-through its interactions on social media.

If the contemporary internet has reconfigured activists' access to audiences, it has also changed the nature of their access to brands. The shift to digital marketing has led to what Sauter (2014, p. 151) dubs "the avatar nature of online brand presence," in which large, distributed corporations are represented by a single website or social media account. As Sauter notes, this creates a strange, if imperfect, symmetry between individuals and organizations, both of which may be represented online by a single website or profile page.

As Sauter describes it, this concentration of large organizations into single sites and accounts also creates a centralized target for campaigns - a handful of activists might not be able to block the entrance to every store in a large retail chain. But online, where the chain is represented by a single website, a small group of hacktivists, using a distributed denial-of-service attack on the retailer's servers, can shutter a multinational business's online presence for hours.

As with websites, there is greater symmetry between users and brands on social media, where a large corporation and an ordinary user each tweet from accounts that follow roughly the same online physics. Brands follow and are followed, tag and are tagged, comment and reply, retweet and are retweeted, in much the same way as other users - and this "avatar-ization" gives activists leverage. Richard Wilson is the co-founder of the Stop Funding Hate campaign in the UK, which focuses on inflammatory rhetoric in British tabloids using tactics that are, in part, similar to those of Sleeping Giants. Namely, Stop Funding Hate lobbies advertisersthrough new and traditional media channels-to pull their ads from publications that print inflammatory antiimmigrant rhetoric. He described this newfound leverage as follows:

For a lot of these big brands-particularly brands who are targeting people under 40 or people under $50-$ their primary strategy for reaching their customers and having a conversation with their customers is social media. So, if you're jumping into that conversation on Twitter and going, "Hang on a minute, you're supposed to be brilliantly inclusive on LGBTQ issues, 
but here you are with this notoriously homophobic newspaper and I'm really disillusioned," you're not just sending them a message. You're sending them a public message and you're doing it right in the space where they've invested lots of marketing budget to be all, kind of chatty and conversational. And you're saying, "Okay, let's have a conversation. And this is what we want to converse about." I think it's totally transformative. (personal communication)

\subsection{Corporate Social Responsibility}

In much the same way we have characterized the spectrum of positions taken by journalism scholars on the appropriate relationship between news and advertising, the literature on activism often places activist groups on a spectrum ranging from "reformist" to "radical" (de Bakker, 2015; den Hond \& de Bakker, 2007), where reformist groups are amenable to working within a system to change it while more radical groups seek to dismantle or abandon systems they view as irretrievably corrupt.

As Carrie A. Rentschler observes, "Many social movements from the political right to the political left make strategic use of the media without also seeking to change the corporate, profit-oriented structure of the media" (2003, p. 530). For example, campaigns, by Sleeping Giants and others, against Fox News personalities whose actions either on the air or in their personal conduct have been found by progressive media activists to be intolerable-from Bill O'Reilly to Tucker Carlson to Laura Ingraham-have targeted companies who advertise during these shows in order to pursue the goal of removing objectionable people or discourse from a major cable news network. Sometimes they succeed (e.g., O'Reilly). At the same time, though, this activism arguably bolsters the system of advertiser-support, and the legitimacy of corporations censoring media content, that is typically anathema to progressive causes (Soley, 2002).

Where Sleeping Giants self-identifies on the political spectrum is a matter we will return to shortly. Given their campaigns typically target right-wing media, however, they are most often labeled in media coverage as progressives. To the extent the label applies, there is an inescapable irony in progressives, in the 21st century, pressuring corporate sponsors as a way to discipline the media, when in the 20th century the corporate sponsor was viewed by many progressives as one of the central limitations to a free, vibrant, and diverse media system. Herbert Schiller wrote, "what can be expected if the channels of expression and the cultural conduits are clogged with corporate speech and values?" (1991, p. 59). As Matthew P. McAllister (1996) wrote, regarding the history of socially conservative groups using campaigns and boycotts targeted at advertisers to censor the television environment:

The most visible boycotts have been, if anything, destructive to democratic society. This is because many boycotts against advertisers, paradoxically, serve to increase the social influence of advertisers. Conservative media critics-such as Donald Wildmon of the American Family Association-often target advertisers of TV programs that they find objectionable....Essentially they coerce advertisers into asserting their economic control over media content. If the boycott is successful, it has increased the power of advertising over media. To stop the boycott, advertisers may withdraw funding from a program, which may send a message to the media that such programs are not wanted. A successful boycott of this kind teaches the media another lesson about the power of advertising. (p. 256)

Progressive activists must decide if using the "master's tools" to dismantle a particular part of his house is the approach they wish to take, as an effective short-term strategy could have unintended long-term consequences (Rentschler, 2003, p. 530).

In the world of online activism, it's easy to see collectives like those behind Anonymous as existing toward the more radical end of the reformist-radical spectrum, engaging in actions intended to dismantle or severely damage targeted organizations like the Church of Scientology or the cybersecurity firm HBGary (Beyer, 2014; Coleman, 2014). Within the world of advertising activism specifically, approaches like "culture jamming," "subvertising," and "Brandalism" occupy the radical end of the spectrum (Lasn, 1999; Lekakis, 2017). Collectively referred to as "tactical media," these strategies take a participatory, interventionist approach to undermining the cultural authority of the advertising ecosystem (Garcia \& Lovink, 1997)-for example, by creating counterfeit advertisements with activist messages that shame targeted brands. Sleeping Giants, meanwhile, represents a much more buttoned-down, reformist approach to digital activism, framing the problem of hate speech as an issue of corporate social responsibility.

When we asked various chapters whether they hoped to get rid of Breitbart News and other far-right publications, we were uniformly told that our question missed the point. To begin with, Breitbart News is supported by private investors, meaning it can still survive without substantial ad revenue. The distinction, however, went beyond this. The activist behind the Sleeping Giants Sweden account gave a representative quote:

The main point is not completely defunding them, because I'm not sure whether that can be done. The main point, to me, is to make sure that it doesn't get normalized to have your ads on websites like that. Because we're on a dangerous road if mainstream companies advertise on those sites and their clients give no reaction. (personal communication)

This points to a key aspect, both of Sleeping Giants as a campaign, and of corporate social responsibility cam- 
paigns more broadly, which is that the ultimate aim is to redefine the bounds of acceptable behavior within a field (de Bakker, 2015; den Hond \& de Bakker, 2007). Sleeping Giants is trying to use the specter of brand damage to change (or restore) the perspective-“field frame" (Lounsbury, Ventresca, \& Hirsch, 2003)-within the industry to one in which brands have a moral responsibility to both know and be selective about where their ads appear.

Though Sleeping Giants confronts brands with the specter of negative publicity, across the board chapters told us they were "an information campaign, not a shame campaign." The idea was that, because of the opacity of the programmatic advertising ecosystem, many advertisers likely had no idea their ads were appearing on Breitbart News or other inflammatory publications. Thus, the activists framed their activities as a service to brands rather than a campaign to shame them into submission.

As Wilson highlights above, however, contacting brands in public rather than over private channels raises the stakes around compliance. And, while Sleeping Giants founder Matt Rivitz told us many brands were appreciative when notified their ads had been appearing on Breitbart, this did not typically result in a warm relationship between the campaigns and the brands they had contacted going forward. "No one wants to talk about it when it's all over," he said. "It's a little like you guys just did something together and then everyone's like, 'Okay, that was weird.' You had a pretty intense date and then no one's calling back afterward" (personal communication).

Rivitz also clarified that the campaign was willing to shame companies. It reserved shaming, however, for the ad-tech companies and social media platforms it saw as being primarily responsible for enabling the monetization of hate speech. But, much like the activists who used advertiser boycotts against network television programming in past decades after finding the networks themselves unresponsive (Fahey, 1991), Rivitz said advertisers were the parties in the equation who were most willing to listen to consumer complaints.

As with the television networks, platforms offer content to users for free and sell their attention to advertisers, recalling the old adage, "If you're not paying for it, you're not the customer, you're the product." Or, as Rivitz framed it more bluntly, "KFC doesn't ask the chickens what they want to do with the company" (personal communication). Advertisers, meanwhile, spend a great deal on cultivating an image of inclusivity around both their customer base and their hiring practices, and are therefore more sensitive regarding threats to this perceptionhence the common industry term, "brand safety," in reference to the ideal that ads should appear only in places unlikely to damage a company's image by association.

A campaign that bills itself as providing a major service to brands is far more reformist than revolutionary. And, as noted above, despite taking aim at far-right media, activism intent on reifying the traditional advertising model might be thought of as inherently conservative in some ways. From the activists' own perspective there are no paradoxes in this. Rivitz explained that standing against hate and bigotry should fundamentally not be viewed as a partisan stance.

\section{An International Movement}

Sleeping Giants' success in the US quickly inspired spinoffs in other countries. Some of these approached the founders of the initial accounts to inquire about creating a new national chapter, while others were individuals who contributed actively to the original social media campaign as ordinary users and were subsequently invited by the existing activists to create accounts in their various home countries. The chapters communicate via a backchannel and informally vet the addition of people and chapters, for example determining if anyone in the existing group can vouch for a new individual.

A good number of the non-US chapters joined in response to the announcement by Breitbart News that the publication would be expanding its operations in Europe, and for many of these chapters the initial aim was to aid the US campaign by advising the advertisers in their respective countries to pull their ads from Breitbart, thus reducing the apparent profit potential of such an expansion.

These chapters operated in the native languages of their home countries and the Sleeping Giants EU account worked, through retweets, to create a centralized record of their various contributions to the list of advertisers blacklisting Breitbart, which could be referenced to update the figures maintained by the US campaign.

In Germany and elsewhere, chapters maintained a relatively narrow focus on Breitbart as a target. The German activist we spoke with said this was for three reasons: 1) Breitbart had announced explicit plans to move into Germany, creating a sense of urgency around halting such an expansion; 2) they assessed most of the local sites that toed or crossed the line into hate speech to be small, and feared targeting them could inadvertently give them publicity; and 3) the existence of a particularly aggressive trolling culture among far-right German social media users raised concerns about doxing and targeted harassment.

As time went on, however, at least some chapters turned their attention to publications closer to home. The Swedish and Dutch activists were especially interested in Breitbart because it had a sizable audience in their home countries. But they quickly identified homegrown publications monetizing inflammatory content as well. In the Netherlands, activists took aim at the commercial publication GeenStijl.

Sleeping Giants Sweden identified Samhällsnytt ("Society News," formerly Avpixlat or "Un-Pixelated") and Nyheter Idag ("News Today") as particularly problematic. According to the Swedish activists, much of the content of these publications consists of loose rewrites of Breitbart material. Both sites, which have ties to 
the Sweden Democrats (a far-right party with ethnonationalist roots) and a more radical splinter party respectively, were identified independently by researchers at the Oxford Internet Institute (Hedman et al., 2018) as leading purveyors of "junk news" in Sweden.

In Switzerland, activists took aim at messages from the Swiss People's Party, which put out anti-migrant materials in the form of inflammatory political advertising (this is the party responsible for the notorious blacksheep billboard image), and a newspaper insert containing misleading statements. They also coordinated with Sleeping Giants France in actions against the French publication $B V$ - to be discussed shortly-which enjoyed a sizable readership among Switzerland's Francophone population.

The Australian chapter, one of the last to join in mid2017, meanwhile focused tightly not on far-right websites, but on the Murdoch news empire in Australiaparticularly the Sky News Australia cable channel, which the activists discussed as the primary platform through which hateful ideas and the personalities conveying them were being mainstreamed into the Australian media ecosystem.

Many of these chapters started in early 2017 and petered out the following year, gradually ceasing to post or retweet. A number of activists noted that European advertisers, who often hadn't thought to blacklist Breitbart because they hadn't anticipated it would have a local readership, were very quick to pull their ads. As such, Wilson conjectured that at least some chapters likely shut down out of a sense their mission had been accomplished.
But as Beyer (2014) has noted, this drop-off is fairly typical for online mobilizations, wherein participation tails away after an initial hot period, but leaves behind "sticky" activists-passionate people mobilized by the campaign who remain committed to the issues that most concerned them and continue to mount effective actions into the future. At the time of this writing, active chapters remain in Canada, the Netherlands, France, and the US.

\subsection{The French Example}

While the limited space of a single article necessarily precludes us from discussing each international Sleeping Giants chapter and the conditions in which it operates in depth, as an example of the campaign's malleability and the ways in which cultural and political contexts have shaped activist actions, here we explore one of these chapters in greater detail. Among the most interesting of the cases is the French chapter of Sleeping Giants, where activists expanded greatly beyond the initial tactics employed by the movement.

To begin with, French law places greater limits on the protection of speech, restricting the ability of activists to label sites as "racist" or "fascist," since they would be asserting criminality and inviting potential legal repercussions. To work around such constraints, the activists created software that sorts inflammatory headlines from $B V$-one of their target sites-based on tags describing the type of inflammatory rhetoric employed. The program creates composite images, like those in Figure 3, which concentrate the site's worst rhetoric into share-

\section{Dourcuang IS THIS:}

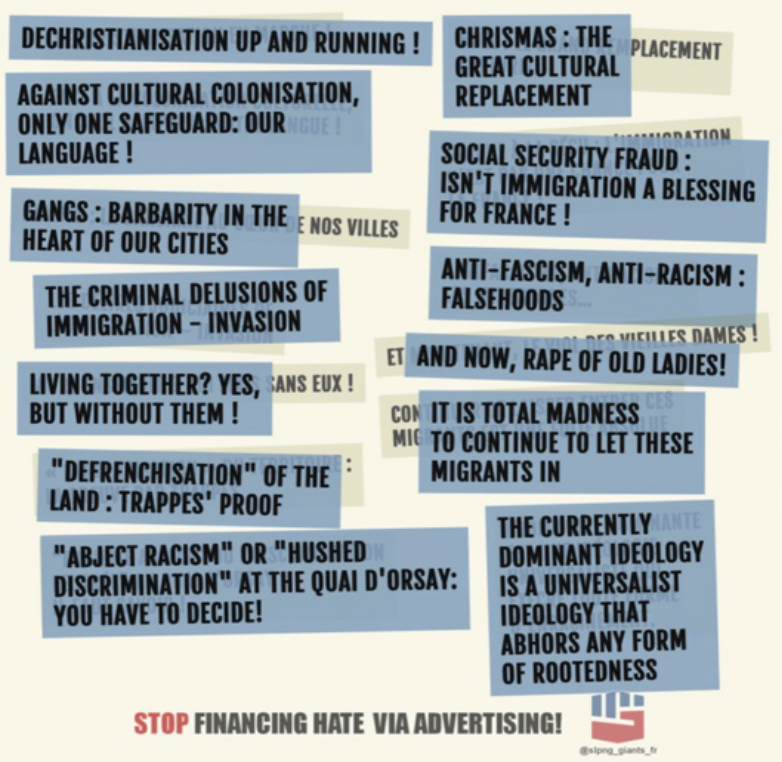

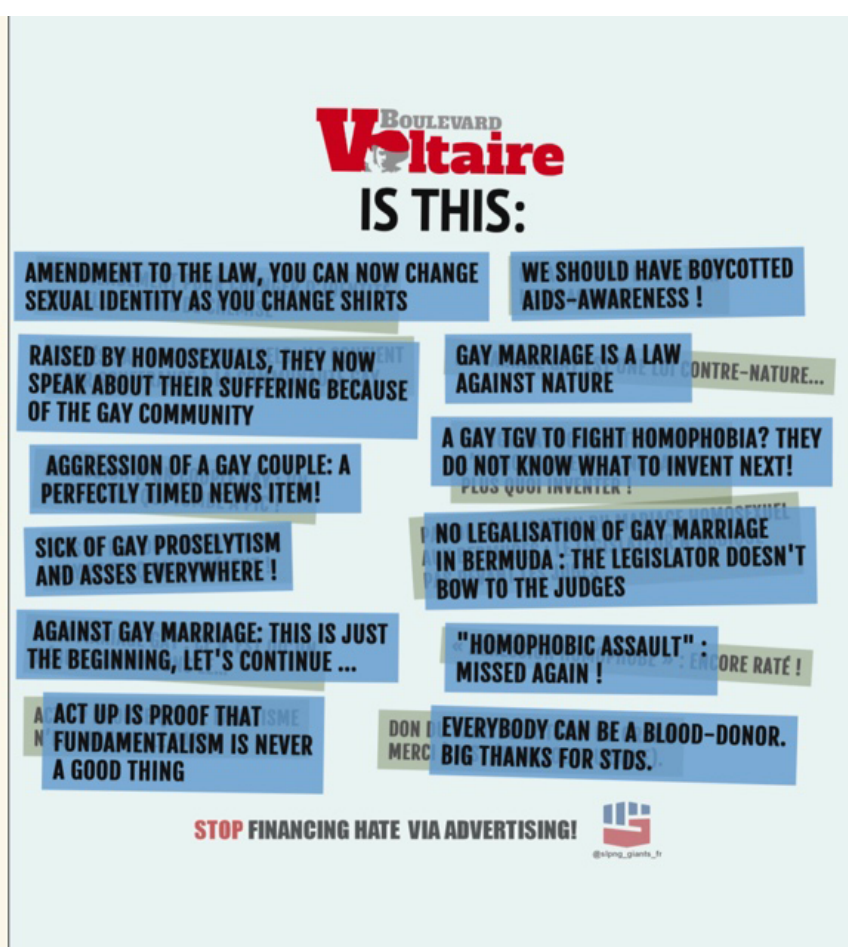

Figure 3. Examples of software-generated graphics from Sleeping Giants France. Notes: New images are generated regularly to leverage the Twitter algorithm's preference for fresh content. Translations courtesy of Sleeping Giants France. 
able graphics designed to make an impact on advertisers. Sharing a graphic of a dozen or so headlines demonizing migrants or another showing misogynist language easily gets the point to advertisers.

As the above example suggests, the French activists are among the most tech savvy of the Sleeping Giants collective. They regularly inspect the source code of $B V-$ the aforementioned French publication, loosely analogous to Breitbart-to identify which ad-tech services are in use on the site (see Figure 4). At one point the campaign had so thoroughly demonetized $B V$ that the site stopped selling ads altogether for a time. The activists' source code inspections also revealed at one point that $B V$ was attempting to compensate for lost revenue by employing crypto-jacking scripts-JavaScript code that enlisted unwitting users' browsers to mine cryptocurrency. Sleeping Giants France quickly publicized this fact, forcing $B V$ to pull the code from its site to avoid angering readers.

Sleeping Giants France has also engaged in actions beyond social media. Perhaps the most illustrative example is the group's response to European white supremacist group Generation Identity's project, "Operation Defend Europe."

Operation Defend Europe was a crowdfunded campaign aimed at launching a boat expedition in the Mediterranean to interfere with migrant rescue efforts. Sleeping Giants France joined other activists in writing to banks in Austria, Italy, Germany, and France to have Generation Identity's accounts closed. They also helped to get the group's accounts on PayPal and various crowdfunding sites blocked.

Generation Identity then turned to WeSearchr to raise funds, an American crowdfunding platform run by white supremacists (and listed by the Southern Poverty Law Center as a hate group). In response, Sleeping Giants France published a public dossier to raise awareness among officials of Generation Identity's plans. Along with other activists, they wrote to port cities, delaying the expedition's launch and later notifying the mayors of port cities where the group might try to land their boat, resulting in these ports being closed to the group by waiting police. Ultimately, Operation Defend Europe ended when the boat, broken down and unable to dock, was rescued and towed into port.

While Sleeping Giants France is quick to point out they collaborated with other activist groups in their actions against Operation Defend Europe, the case serves as an example not only of how a chapter adapted Sleeping Giants' basic tactics to its local context, but how it extended the basic mission statement of the movement-"to make bigotry and sexism less profitable" - to a different domain, intervening in a crowdfunded operation by white supremacists.

\section{Anonymity and Collaboration}

With two notable exceptions-Matt Rivitz, who was unmasked by the conservative media outlet, the Daily Caller, and Nandini Jammi, who partners in the work on the US account and whose identity was revealed in subsequent reporting by the New York Times-all of the activists behind the various Sleeping Giants chapters have remained anonymous. The choice to remain anonymous was typically framed as having to do with a combination of concerns.

First, many of the activists in their day jobs had some relationship to marketing, advertising, or media-

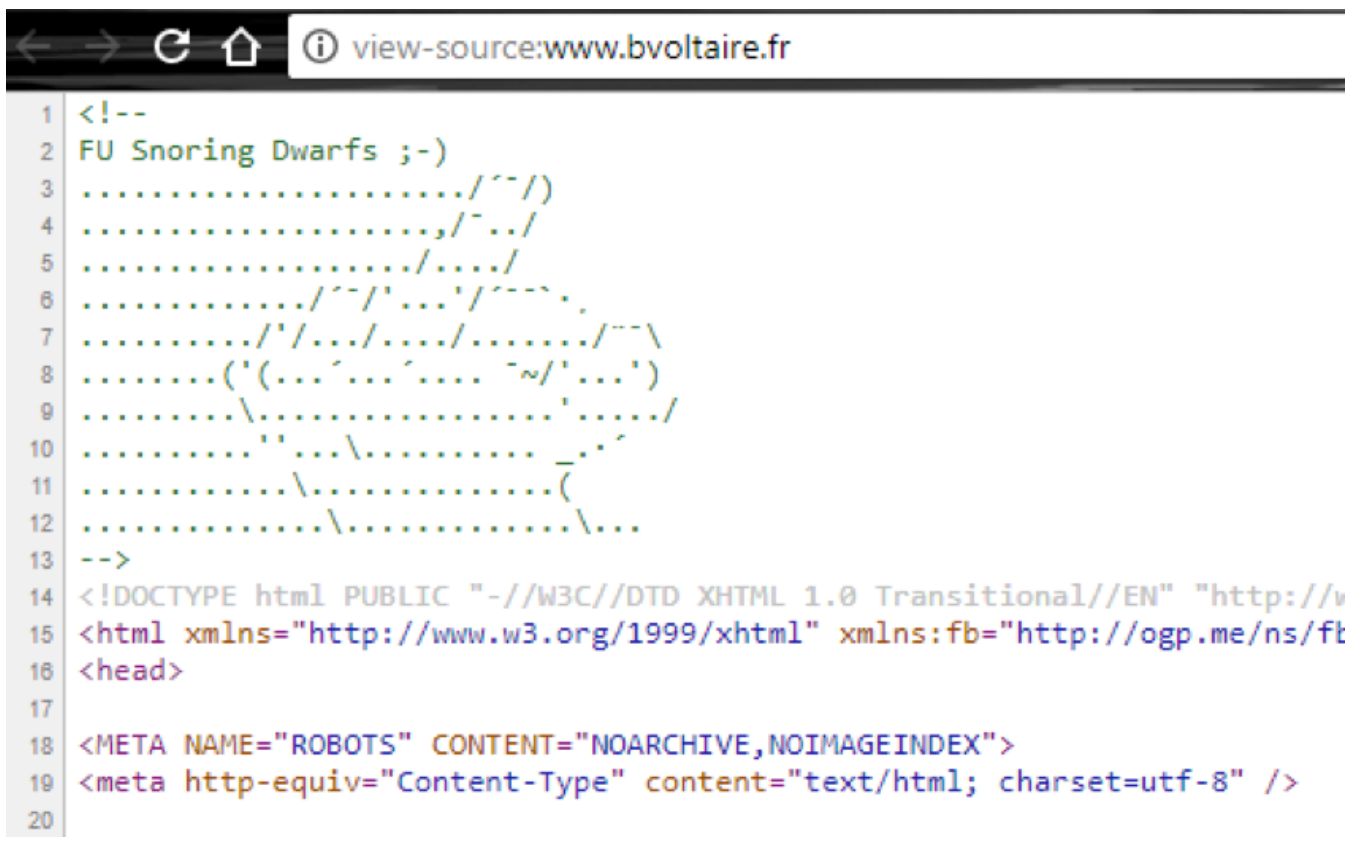

Figure 4. $B V$ became aware Sleeping Giants France was inspecting their source code and inserted this HTML comment into their pages for the activists to find. 
another key reason for the group's reformist stanceand worried their careers or client relationships might be impacted were their identities revealed. Second, as Marwick and Lewis (2017) have documented, critics of the far right and "alt-right" are often subjected to doxing and targeted online harassment. Finally, there was concern that were the activists to identify themselves, their personalities could at best serve as a distraction and at worst invite opponents to attempt to discredit the movement by sullying the reputation of individuals.

It's worth noting, too, Sleeping Giants' approach combines advantages of both identity and anonymity. Advertisers see the accounts of the ordinary, identified users it amplifies through retweets, giving messages the sheen of authenticity. Simultaneously, the absence of identifying information on the activist accounts suggests an imposing collective in the style of Anonymous. Jessica Beyer (personal communication, 2019) notes that whereas in the case of Anonymous, anonymity began as a technical constraint of the 4chan message boards and evolved into one of the group's core values, Sleeping Giants-having learned by example the advantages anonymity provided-adopted it as a strategy on social media platforms where real names are the default.

Sleeping Giants activists communicate through backchannels that also allow them to remain anonymous to one another (if they do not already know one another's identities, which is most often the case). Rivitz described the atmosphere by referencing the film Reservoir Dogs, which famously features a group of thieves who know one another only by pseudonyms. Mostly, the group communicated to vet new chapters, seek advice, share domain-specific expertise, or request retweets to amplify their messages when the fate of a major advertiser was on the line. But, as the different directions taken by various chapters suggest, they in many ways operate independently of one another.

Collaborations with outside activist groups were also greatly beneficial. For example, Richard Wilson of Stop Funding Hate was able on occasion to effectively make the group's concerns heard in institutional settings where anonymity would otherwise have been a barrier to participation. Most notably, he discussed Sleeping Giants' work alongside that of his own campaign in front of the United Nations, which subsequently inserted language on ethical advertising into the 2018 Global Compact on Migration, which supports the demonetization of media outlets that systematically promote intolerance toward migrants.

\section{Conclusion}

As Sleeping Giants chapters have withered in many countries, some of those that remain are looking to create more formal and sustainable structures around their activism. Several chapters expressed a desire to help create a set of standards for ethical advertising-formal guidelines for ad placement to which brands could adhere to gain a seal of approval, changing the relationship between activists and brands from a stick to a carrot.

In the US, the exposure of Rivitz and Jammi's identities has also opened a new chapter for the movement. While the revelation brought death threats from internet trolls and sabre rattling by Breitbart's lawyers, Rivitz has attempted to leverage the spotlight placed on his identity, writing op-eds, appearing in the national media, and speaking to the industry in formal settings that would've been inaccessible previously. Jammi likewise utilized her newfound prominence to pressure PayPal into dropping the KKK as a customer, among other endeavors.

Though the loose online collective may continue to exist in some form, at least some corners of the Sleeping Giants movement appear poised to make the transition from internet-based to internet-enabled activism (van Laer \& van Aelst, 2010) and to a more formal institutional presence.

Beyer (2014), in examining the trajectory of digital activism, suggests online mobilization often involves the emergence within internet spaces of particular value statements that subsequently become boundary objects (Star \& Griesemer, 1989). As they circulate through online channels, these statements of values are adapted by adherents to the particulars of the local cultural and legal contexts they inhabit.

Sleeping Giants' mission statement-to make bigotry and sexism less profitable-certainly fits this bill. The values Beyer discusses in relation to Anonymous and The Pirate Bay center around free speech, whereas the Sleeping Giants case is more about shared concern over the appropriate limits of speech; this points to distinctions in both the actors involved and the political moment. But her observation that a broad, unifying value can be a precursor to online mobilization across a wide swathe of geographic and cultural contexts holds well in the present case. The examples of different international chapters show how the original activists' concern-the profitability of hate speech-was adapted to different cases, from political advertising that demonizes migrants in Switzerland, to legacy media with intolerant messages in Australia, to crowdfunding by white supremacists in France, and elsewhere.

Much as John Lennon's 1969 motto "give peace a chance," was intentionally contrasted with complex political arguments, the simplicity of Sleeping Giants' mission statement-and its tactics-also stand in effective contrast to claims by digital platforms about the spiraling complexity involved in improving moderation and reforming programmatic advertising. This contrast is one the activists are quick to leverage strategically, pointing to their successes as a group of ragtag volunteers as counterevidence to the platforms' arguments. As a Sleeping Giants France activist put it, "there are companies who make billions out of advertising every year who have all the means, the technology, the staff, the knowledge to do what we're doing. And they don't. So there is a big problem here" (personal communication). 
This quote raises a key point. Examined through the lens of the ad-supported journalism debate, Sleeping Giants is clearly reformist. But the campaign is not solely about disciplining media that traffic in hate speechwhich they see as having a right to exist, though not to ad dollars-or chastening advertisers, for whom they see themselves as providing a service. To the extent that Sleeping Giants' work is about bludgeoning ad-tech firms and dominant online platforms for business practices that uncritically amplify and monetize hate, the campaign takes on a decidedly less reformist, if not necessarily radical, cast. After all, advocating significant structural changes to address societal harms generated by Google and other tech giants is a position familiar to Pickard (2014) and other media critics who favor more "revolutionary" approaches to media reform.

\section{Acknowledgments}

The authors would like to thank Jessica Beyer, Fenwick McKelvey, Jen Schradie, and Susan Benesch for helpful conversations that informed this work. Additionally, we would like to thank Francesca Tripodi, Vlad Barash, and Caroline Jack for their assistance in thinking through our initial research protocol-especially the data and privacy protections involved. We also appreciate transcription assistance from Zoë Cullen.

\section{Conflict of Interests}

The authors declare no conflict of interests.

\section{References}

Baker, C. E. (2001). Media, markets, and democracy. New York, NY: Cambridge University Press

Bell, E., \& Owen, T. (2017). The platform press. New York, NY: Tow Center.

Bennett, W. L., \& Segerberg, A. (2012). The logic of connective action: Digital media and the personalization of contentious politics. Information, Communication \& Society, 15(5), 739-768.

Beyer, J. L. (2014). Expect us. New York, NY: Oxford University Press.

Bhattarai, A. (2017, June 8). Breitbart lost 90 percent of its advertisers in two months. Washington Post. Retrieved from https://www.washingtonpost.com/ news/business/wp/2017/06/08/breitbart-lost-90percent-of-its-advertisers-in-two-months-whosstill-there/

Braun, J. A., \& Eklund, J. L. (2019). Fake news, real money: Ad tech platforms, profit-driven hoaxes, and the business of journalism. Digital Journalism, 7(1), 1-21.

Bruns, A. (2008). Blogs, Wikipedia, Second Life, and beyond. New York, NY: Peter Lang

Coleman, G. (2014). Hacker, hoaxer, whistleblower, spy. New York, NY: Verso.

Couldry, N., \& Turow, J. (2014). Advertising, big data, and the clearance of the public realm. International Journal of Communication, 8, 1710-1726.

de Bakker, F. G. A. (2015). Online activism, CSR and institutional change. In J. Uldam \& A. Vestergaard (Eds.), Civic media and social engagement (pp. 23-43). New York, NY: Palgrave Macmillan.

den Hond, F., \& de Bakker, F. G. A. (2007). Ideologically motivated activism. Academy of Management Review, 32(3), 901-924.

Fahey, P. M. (1991). Advocacy group boycotting of network television advertisers and its effects on programming content. University of Pennsy/vania Law Review, 140(2), 647-709.

Faris, R., Robert, H., Etling, B., Bourassa, N., Zuckerman, E., \& Benkler, Y. (2017). Partisanship, propaganda, and disinformation. Cambridge, MA: Berkman Klein Center for Internet and Society.

Fenton, N., \& Freedman, D. (2017). Fake democracy, bad news. Socialist Register, 54, 130-149.

Friedman, M. (1999). Consumer boycotts. New York, NY: Routledge.

Garcia, D., \& Lovink, G. (1997). The ABC of tactical media. Tactical Media Network. Retrieved from https://www.nettime.org/Lists-Archives/nettime-I9705/msg00096.html

Glaser, B., \& Strauss, A. (1967). The discovery of grounded theory. Chicago, IL: Aldine.

Habermas, J. (2007, May 21). How to save the quality press? Signand-Sight.com. Retrieved from http:// www.signandsight.com/features/1349.html

Hedman, F., Sivnert, F., Kollanyi, B., Narayanan, V., Neudert, L., \& Howard, P. N. (2018). News and political information consumption in Sweden: Mapping the 2018 Swedish general election on Twitter. Oxford, UK: Oxford Internet Institute. Retrieved from https://comprop.oii.ox.ac.uk/wp-content/uploads/ sites/93/2018/09/Hedman-et-al-2018.pdf

Herman, E. S., \& Chomsky, N. (2008). Manufacturing consent. New York, NY: Random House.

Lasn, K. (1999). Culture jam. New York, NY: HarperCollins.

Lekakis, E. J. (2017). Culture jamming and Brandalism for the environment. Popular Communication, 15(4), 311-327.

Lounsbury, M., Ventresca, M., \& Hirsch, P. M. (2003). Social movements, field frames and industry emergence: A cultural-political perspective on US recycling. Socio-Economic Review, 1(1), 71-104.

Malthouse, E. C., Maslowska, E., \& Franks, J. (2018). The role of big data in programmatic tv advertising. In V. Cauberghe, L. Hudders, \& M. Eisend (Eds.), Advances in advertising research IX (pp. 29-42). Wiesbaden: Springer.

Marwick, A., \& Lewis, R. (2017). Media manipulation and disinformation online. New York, NY: Data \& Society Institute.

McAllister, M. P. (1996). The commercialization of American culture. Thousand Oaks, CA: Sage.

McChesney, R. W., \& Nichols, J. (2010). The death and life 
of American journalism. New York, NY: Nation Books. McStay, A. (2017). Micro-moments, liquidity, intimacy and automation. In G. Siegert, M. B. Rimscha, \& S. Grubenmann (Eds.), Commercial communication in the digital age (pp. 143-159). Munich: De Gruyter.

Melford, C., \& Fagan, C. (2019). Cutting the funding of disinformation: The ad-tech solution. London: Global Disinformation Index.

Phillips, W. (2018). The oxygen of amplification. New York, NY: Data \& Society Institute.

Pickard, V. (2014). America's battle for media democracy. New York, NY: Cambridge University Press.

Rentschler, C. A. (2003). Expanding the definition of media activism. In A. N. Valdivia (Ed.), A companion to media studies (pp. 529-547). Malden, MA: Blackwell.

Sauter, M. (2014). The coming swarm. New York, NY: Bloomsbury.

\section{About the Authors}

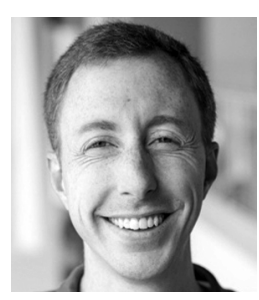

Joshua A. Braun (PhD) is Associate Professor of Journalism at the University of Massachusetts Amherst. His book on digital distribution of TV news, This Program is Brought to You By..., was published in 2015 by Yale University Press, and his articles on sociological questions surrounding online media distribution have appeared in well-regarded journals in communication and journalism studies. Josh is co-editor of "Distribution Matters," a forthcoming series of books on media distribution from The MIT Press.

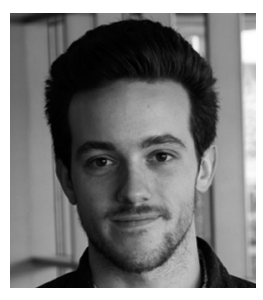

John D. Coakley (BA) graduated from the University of Massachusetts Amherst in 2018 with a degree in Journalism and Political Science. He is currently a Production Editor working in academic publishing in the Greater Boston Area. John is interested in studying the rapidly-changing media landscape and examining how it intersects with geopolitics. In addition to collaborating on research in the UMass Journalism Department, he also assisted research in the Political Science Department examining political endorsements in the 2016 US presidential election.

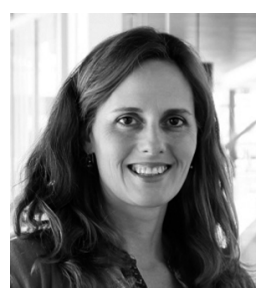

Emily West (PhD) is Associate Professor of Communication at the University of Massachusetts Amherst. She is Co-Editor of The Routledge Companion to Advertising and Promotional Culture (2013) and author of articles and book chapters on digital media and promotional culture, media and nationalism, and critical health communication. Her book project in progress is titled Branding Ubiquity: Amazon, Digital Distribution, and Platform Capitalism, with The MIT Press. 